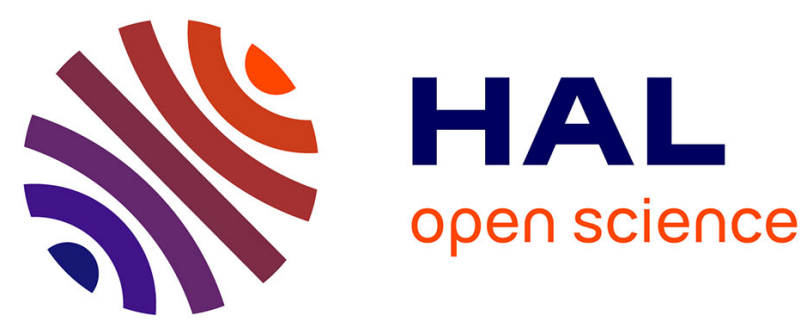

\title{
Archaeological Zelliges of Meknes (14th-century): Physical measurements of the colour and identification of colouring agents
}

Ayed Ben Amara, Adila Azzou, Moustapha Haddad, Max Schvoerer, Claude Ney, S. Ait Lyazidi, P. Molinié

\section{To cite this version:}

Ayed Ben Amara, Adila Azzou, Moustapha Haddad, Max Schvoerer, Claude Ney, et al.. Archaeological Zelliges of Meknes (14th-century): Physical measurements of the colour and identification of colouring agents. Journal de Physique IV Proceedings, 2005, 123, pp.207 - 211. 10.1051/jp4:2005123036 . hal-01900212

\section{HAL Id: hal-01900212 \\ https://hal.science/hal-01900212}

Submitted on 14 Nov 2018

HAL is a multi-disciplinary open access archive for the deposit and dissemination of scientific research documents, whether they are published or not. The documents may come from teaching and research institutions in France or abroad, or from public or private research centers.
L'archive ouverte pluridisciplinaire HAL, est destinée au dépôt et à la diffusion de documents scientifiques de niveau recherche, publiés ou non, émanant des établissements d'enseignement et de recherche français ou étrangers, des laboratoires publics ou privés. 


\title{
Archaeological Zelliges of Meknes (14th-century): Physical measurements of the colour and identification of colouring agents
}

\author{
A. Ben Amara ${ }^{1}$, A. Azzou ${ }^{2}$, M. Haddad ${ }^{2}$, M. Schvoerer ${ }^{1}$, C. Ney ${ }^{1}$, \\ S. Ait Lyazidi ${ }^{2}$ and P. Molinié ${ }^{3}$
}

${ }^{1}$ Centre de Recherche en Physique Appliquée à I'Archéologie (CRPAA), Université de Bordeaux 3, CNRS, 33607 Pessac Cedex, France

${ }^{2}$ Laboratoire de Spectronomie Physique, Faculté des Sciences, BP. 4010 Beni M'hamed, 50000 Meknes, Maroc

e-mail:mhaddad@fsmek.ac.ma

${ }^{3}$ Institut des Matériaux Jean Rouxel de Nantes, 2 rue de la Houssinière, BP. 32229, 44322 Nantes Cedex 3, France

\begin{abstract}
Two series of Zelliges belonging to the Filalia and Bou-Inaniya Medersas (14th-century) in Meknes city have been studied in order to describe precisely the colour of the glazes and to identify the chromogen agents responsible for these colours. The glaze colours are physically studied by the determination of their chromatic coordinates using chromametry method. These coordinates are represented in the conventional Yxy and $\mathrm{L}^{*} \mathrm{a}^{*} \mathrm{~b}^{*}$ spaces. Furthermore the chromogen ions, responsible for the different colour shades, are identified by optical absorption spectrometry (OAS) and by electron paramagnetic resonance (EPR) methods. These ions are the classical ones: copper $\left(\mathrm{Cu}^{2+}\right)$ for the green, cobalt $\left(\mathrm{Co}^{2+}\right)$ for the blue, iron $\left(\mathrm{Fe}^{3+}\right)$ for the honey colour and iron $\left(\mathrm{Fe}^{3+}\right)$ in association with manganese $\left(\mathrm{Mn}^{3+}\right)$ for the black.
\end{abstract}

\section{INTRODUCTION}

The term "Zelliges" indicates pieces of glazed ceramic carefully cut, in geometrical motives, and assembled to give traditional forms. The Zelliges are composite materials associating baked clay and glaze. The particular art of Zelliges had been developed in Morocco since the 11th-century for the decoration of minarets, walls, grounds, columns of religious, military and funeral building and also private houses [1]. Nevertheless during the restoration of these decorations, architects are led to envisage the replication of the disappeared elements. They have to try hard to produce them in the exact traditional manner, this requires the knowledge of their characteristics and in particular those of the glaze colour. The definition of the colour of an object is subjective, because it depends on the nature of the incidental light, the surface state of the object, the spectral sensibility of the observer's eye and on his education to differentiate colours. Hence, the absolute definition of a colour must be made only with physical measurements.

The present work relates to the physical study of glaze colours of several Zellige samples taken from two historical sites of the 14th-century: the Bou-Inaniya and the Filalia Medersas in Meknes (Morocco). The physical methods used are chromametry, optical absorption spectrometry (OAS) and electron paramagnetic resonance (EPR).

\section{EXPERIMENTAL}

Three Zellige samples belonging to Bou-Inaniya Medersa (Mek111, Mek121, Mek113) and four other Zellige samples originating from Filalia Medersa (Mek210, Mek211, Mek212, Mek213) are studied. The optical absorption spectra were recorded on an UV-Visible Varian-Cary spectrophotometer. The calibration of the system and the measure of the background noises were realised using a reference white 
in Teflon. The chromatic coordinates and the associated dominant wavelengths were calculated from the optical spectra. The graphic modes of the chosen representation correspond to the Yxy system (CIE 1931), because of its general use [2], and $\mathrm{L}^{*} \mathrm{a} \mathrm{b}^{*}$ system (CIE 1976) permitting a better separation of distances between colours. The EPR spectra of glazes carefully separated from their ceramic supports are recorded on X-band Bruker spectrometer $(9.5 \mathrm{GHz})$.

\section{RESULTS AND DISCUSSION}

\subsection{Physical description of the colour}

Table 1 shows the chromatic coordinates of the Zellige calculated from the optical spectra in the Yxy and L*a*b* systems (Fig. 1). The colours of the green Zelliges are situated in the green area $(497-530 \mathrm{~nm})$ [3] and present weak reflectance (Y). The green of the sample Mek121 is located at the first part of the green zone with a dominant wavelength equal to $497 \mathrm{~nm}$ (Fig. 1a). The green of the Zellige Mek211 is dark, the corresponding dominant wavelength is $507.11 \mathrm{~nm}$. The colour of the sample Mek212 is dark blue, with a dominant wavelength equal to $480.33 \mathrm{~nm}$. This colour is not saturated, its

Table 1. Chromatic Coordinates, in the Yxy and $\mathrm{L}^{*} \mathrm{a} \mathrm{b}^{*}$ systems, of the Zellige glazes studied and their associated dominant wavelength $\lambda_{d}$ and excitement purity $\mathrm{P}_{\mathrm{e}}$.

\begin{tabular}{|c|c|c|c|c|c|c|c|c|c|c|}
\hline & Colour of glaze & $\lambda(\mathrm{nm})$ & $\mathbf{P}_{\mathbf{e}}(\%)$ & $\mathbf{Y}$ & $\mathbf{x}$ & $\mathbf{y}$ & $\mathbf{L}^{*}$ & $\mathbf{a}^{*}$ & $\mathbf{b}^{*}$ & $\begin{array}{l}\text { Corresponding } \\
\text { colour }\end{array}$ \\
\hline \multirow{4}{*}{$\begin{array}{c}\text { Bou-Inaniya } \\
\text { Medersa }\end{array}$} & Mek113, honey & 582.64 & 54.27 & 16.227 & 0.431 & 0.405 & 47.271 & 10.314 & 30.6 & Dark yellow-orange \\
\hline & Mek121, green & 497.11 & 13.52 & 17.155 & 0.273 & 0.348 & 48.455 & -17.224 & -0.141 & Dark green \\
\hline & Mek111, black & 478.06 & 3.61 & 5.212 & 0.305 & 0.321 & 27.329 & -0.049 & -1.674 & Black \\
\hline & Mek211, green & 507.11 & 13.61 & 12.793 & 0.271 & 0.379 & 42.45 & -22.854 & 5.442 & Dark green \\
\hline \multirow{3}{*}{$\begin{array}{c}\text { Filalia } \\
\text { Medersa }\end{array}$} & Mek210, white & 573.53 & 17.68 & 49.98 & 0.34 & 0.365 & 76.057 & -2.411 & 14.956 & White \\
\hline & Mek212, blue & 480.33 & 18.86 & 14.664 & 0.271 & 0.293 & 45.171 & -2.401 & -11.664 & Dark blue \\
\hline & Mek213, black & 594.44 & 4.79 & 8.126 & 0.327 & 0.332 & $\mid 34.243$ & 2.39 & 1.705 & Black \\
\hline
\end{tabular}

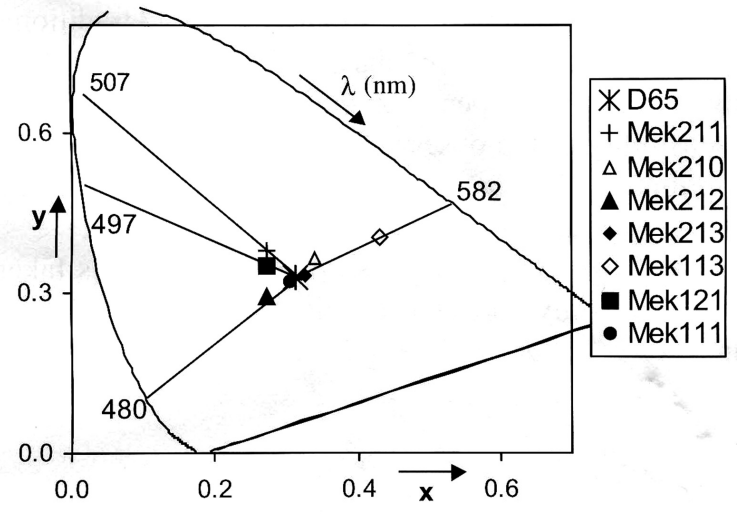

a)

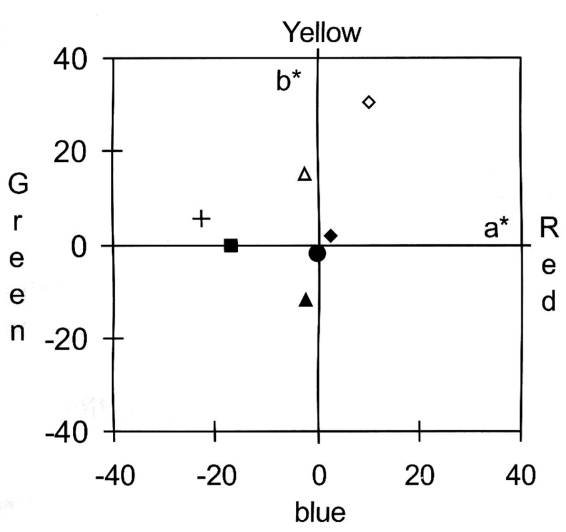

b)

Figure 1. Graphic representation in the chromatic $Y x y$ (a) and $L * a * b *(b)$ spaces of the points corresponding to the glaze colours of the Zelliges. The dominant wavelengths $\lambda_{d}$ are indicated in the Yxy space (except for white and black glazes). 
excitation purity $\mathrm{P}_{\mathrm{e}}$ is weak of about $18.86 \%$. The colour of the honey Zellige Mek113 is situated in the yellow-orange-coloured region $(580-585 \mathrm{~nm})$ [3]. This colour is relatively saturated $\left(\mathrm{P}_{\mathrm{e}}=54.27 \%\right)$. The chromatic coordinates of the black Zelliges Mek111 and Mek213 and the white Zellige Mek210 are situated in the central part of the "windsurfing board" of the Yxy space (Fig. 1a), close to the coordinates of the D65 illuminating standard $(x=0,313$ and $y=0.329)$. The black Zelliges present weak reflectance $(<10)$ and the white Zellige a strong reflectance $(\approx 50)$ (Table 1$)$. The colour of the white Zellige is shaded yellow as shown by the value of the dominant wavelength: $\lambda_{d}=573.53 \mathrm{~nm}$ (yellow: $575-580 \mathrm{~nm}$ [3]) and also by the values of $a^{*}$ and $b^{*}$ (Fig. 1b).

\subsection{Identification of chromogen agents}

Fig. 2 shows two examples of the optical spectra of the Zellige. In the case of the green glaze sample (Fig. 2a), the spectrum exhibits a wide band between 550 and $900 \mathrm{~nm}$ characteristic of $\mathrm{Cu}^{2+}$ ions in glassy phase [4]. The presence of $\mathrm{Cu}^{2+}$ ions in the green glazes is also revealed in their EPR spectra (Figs. $3 \mathrm{a}$ and $3 \mathrm{~b}$ ). The first one shows essentially $\mathrm{Cu}^{2+}$ rays overlapping with a line of weak intensity located around $\mathrm{g} \approx 4.3$ characteristic of $\mathrm{Fe}^{3+}$ ions. The second spectrum reveals, in addition to the precedent bands, an other wide line relatively intense around $\mathrm{g} \approx 2$. This latter line is attributed to pairs of $\mathrm{Fe}^{3+}$ ions while the first one is due to isolated $\mathrm{Fe}^{3+}$ ions [5,6]. Furthermore, the EPR spectra tend to show that copper and iron amounts are higher in the case of the Mek211 glaze than in the Mek121 one. This result is in agreement with those of chromametry. Indeed, a higher copper amount explains the more green colouring of the Mek211 glaze. On the other hand, more $\mathrm{Fe}^{3+}$ amount increases the chromatic coordinates in the $\mathrm{L}^{*} \mathrm{a}{ }^{*} \mathrm{~b}$ space. That's the case because the yellow component is more important in the Mek211 glaze than in the Mek121 one (Fig. 1b).

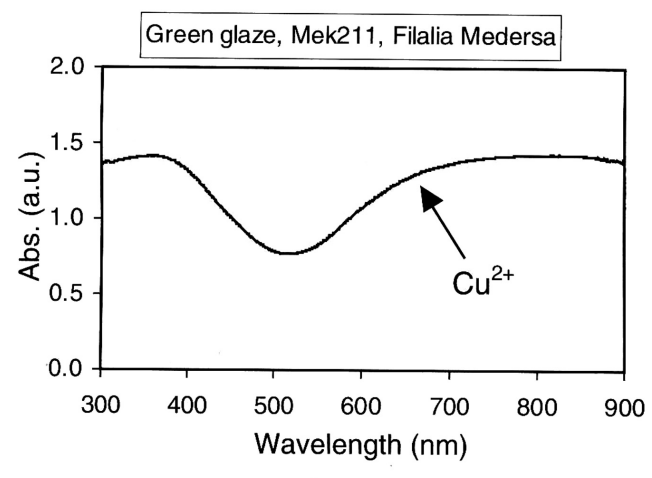

a)

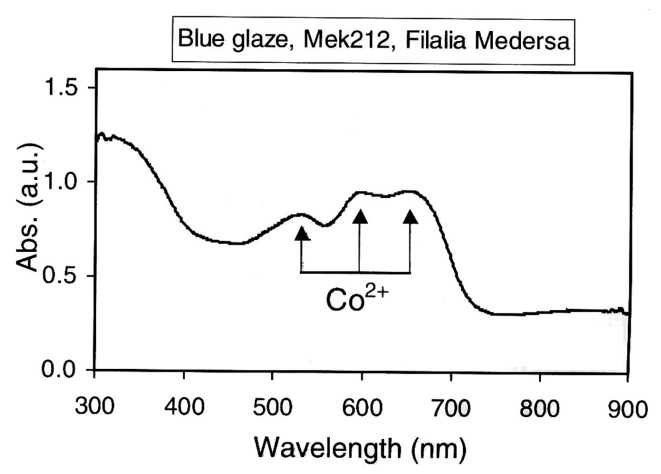

b)

Figure 2. Optical spectra of the green Zellige Mek211 (a) and the blue Zellige Mek212 (b).

The optical spectrum of the honey glaze Mek113 presents two shoulders around 430 and $380 \mathrm{~nm}$ attributed to $\mathrm{Fe}^{3+}$ ions [4]. The corresponding EPR spectrum (Fig. 3c) reveals the existence of two kinds of $\mathrm{Fe}^{3+}$ ions. This spectrum contains an intense line at $\mathrm{g} \approx 2$ relative to $\mathrm{Fe}^{3+}$ clusters and a weak line at $\mathrm{g} \approx 4.3$ due to isolated $\mathrm{Fe}^{3+}$ ions. The optical spectrum of the blue glaze Mek212 (Fig. 2b) exhibits three bands around 540, 594 and $640 \mathrm{~nm}$ characteristic of $\mathrm{Co}^{2+}$ ions which have strong blue colouring effect even as traces [7,8]. This spectrum shows, at the same time, two shoulders around 380 and $440 \mathrm{~nm}$ due to $\mathrm{Fe}^{3+}$ ions. The EPR spectrum of the blue glaze (Fig. 3d) shows clearly the superimposition of the $\mathrm{Co}^{2+}$ and $\mathrm{Fe}^{3+}$ signals. Because of the weak relaxation time of the $\mathrm{Co}^{2+}$, the corresponding EPR line was detected at low temperature [9]. The weak intensity of the line at $\mathrm{g} \approx 2$ indicates that the amount of the cobalt in the material is very weak. The presence of the iron in the glaze induced shading of the 


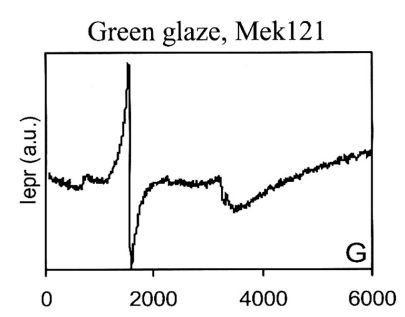

a)

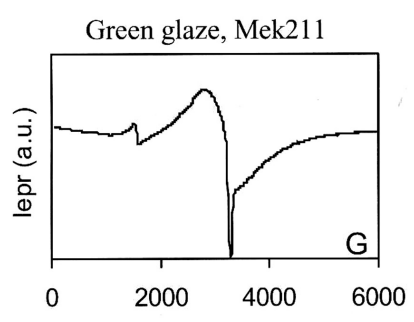

b)

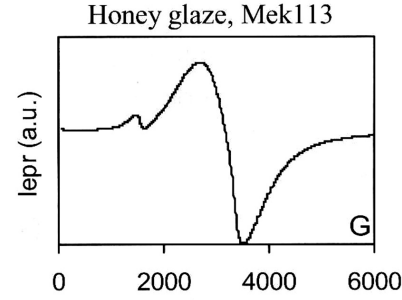

c)

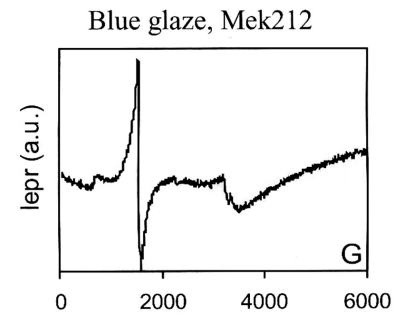

d)

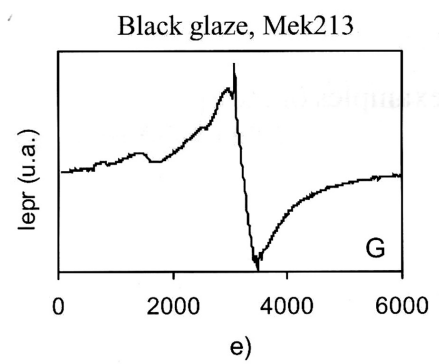

Figure 3. EPR spectra of the glazes of zelliges. Green glazes Mek121 (a) and Mek211 (b), honey glaze Mek113 (c), blue glaze Mek212 (d) and black glaze Mek213 (e).

blue colour. The absorption spectra of the black glazes Mek111 and Mek213 show strong absorption in all the visible domain, this can correspond to superimposition of several bands. An attentive observation permits to distinguish a first shoulder in the visible area around $500 \mathrm{~nm}$ likely due to the presence of $\mathrm{Mn}^{3+}$ ions [4], and a second shoulder in the ultraviolet area around $380 \mathrm{~nm}$ probably due to $\mathrm{Fe}^{3+}$ ions. This assumption is in agreement with the corresponding EPR spectra confirming the simultaneous presence of manganese and iron in these glazes. The EPR spectrum of the Mek213 glaze (Fig. 3e) is constituted by lines of $\mathrm{Fe}^{3+}$ superimposed to other signals which may be explained by the presence of $\mathrm{Mn}^{2+}$ ions in the glaze. The detection of $\mathrm{Mn}^{2+}$ ions suggests the presence of $\mathrm{Mn}^{3+}$ ones (oxidizing atmosphere). Furthermore, the combination of $\mathrm{Mn}^{3+}$ and $\mathrm{Fe}^{3+}$ ions induces black colouring of the glazes [8].The optical spectrum of the white glaze Mek210 exhibits a large band lying from 200 to $400 \mathrm{~nm}$.

This band is the overlap of two close bands located around 220 and $250 \mathrm{~nm}$, and a third band located around $380 \mathrm{~nm}$. The two former bands are related to the charge transfer transitions implying oxygen anions and iron cations. These charge transfer transitions are associated with $\mathrm{Fe}^{2+}$ and $\mathrm{Fe}^{3+}$ ions respectively, they might be at the origin of the colours of the glasses [10]. The third band situated around $380 \mathrm{~nm}$ may be related to $\mathrm{Fe}^{3+}$ ions giving generally yellow coloration to the glazure [5]. The $\mathrm{Fe}^{3+}$ ions were also detected by EPR and would be responsible for the yellow shade of the white glaze.

\section{CONCLUSION}

The obtained results allowed us to realise an absolute description of the colours of glaze Zelliges in view to control the chromatic quality of recreated Zelliges for restoration. The identification of chromogen ions was accomplished without ambiguity owing to the complementarity of the optical absorption and the EPR spectroscopies. Furthermore this later technique permitted to obtain supplementary information on the distribution of the ions.

\section{Acknowledgements}

This work was supported by EU Commission (Contract number ICA-3-CT-1999-00002) and CNRST-Morocco (PROTARS P7T3 / 2000 and Convention CNRS). 


\section{References}

[1] Cambazard-Amahan C.,Zillig: l'art de la céramique marocaine (Hedgecoe J., Damluji S.S. Ed., Garnet, 1993) pp.136-154.

[2] Kowaliski P., Vision et mesure de la couleur (Collection Physique Fondamentale et Appliquée, $2^{\mathrm{e}}$ ed., Masson, 1990) pp. 124-189.

[3] Kelly K.L., Judd D.B., Color - Universal Color Language and Dictionnary of Color Names (National Bureau of Standards, New York, Special Publication, 1976) 440.

[4] Lajarte S., Les verres colorés (L'actualité chimique, 1979) pp. 30-36.

[5] Boudlich D., Yahiaoui E.M., Archidi M.E., Haddad M., Nadiri A., Berger R., An. Chim. Sci. Mat. 23 (1998) 113-116.

[6] Haddad M., Boudlich D., Archidi M.E., Bentayeb A., Nadiri A., Phys. Chem. News 3 (2001) 37-39.

[7] Dubernet S., Schvoerer M., Verre 2 (1996) 26-33.

[8] Rhodes D., Terres et glaçures (Dessain et Tolra, Paris, 1999) pp.128-147.

[9] Mouhsine N., Bih L., Allali N., Nadiri A., Yacoubi A., Hadad M., Danot M., Sol St Sc 5(2003)669 675.

[10] Nassau K., 1998, Fundamentals of color sc (Color for sc, art \& tech, Elsevier Sc, 1998) pp.125-167. 